\title{
Effect of tempering temperature on microstructures and properties of niobium and titanium microalloying low carbon bainite steel
}

\author{
Defa $\mathrm{Li}^{1,2, \mathrm{a}}$, Feng Huang ${ }^{3, \mathrm{~b}}$, Shisen Wang ${ }^{1, \mathrm{c}}$, Yuzhang Xiong ${ }^{1, \mathrm{~d}}$, Shuqing \\ Xing $^{2, e}$, Tao Xiong ${ }^{1, f}$ \\ ${ }^{1}$ Research and Development Center of Wuhan Iron and Steel Group, 430080, China \\ ${ }^{2}$ School of Materials and Metallurgy, Inner Mongolia University of Science and Technology, 014010, \\ China \\ ${ }^{3}$ School of Automotive Engineering, Wuhan University of Technology, 430070, China \\ a303_lee@163.com, ${ }^{b}$ hfwin_006@126.com, czwss@me.com, 'xiongyuzhang2006@126.com, \\ exingshuqing312@163.com, traoxiong@163.com
}

Keywords: Effect; Tempering temperature; Niobium and Titanium microalloying; Bainite steel

\begin{abstract}
The effect of tempering temperature on microstructures and mechanical properties of niobium and titanium microalloying low carbon bainite steel was investigated. The results indicate that the mechanical properties change is mainly controlled by the structure evolution, and as the structure evolution during tempering is complex, the mechanical properties do not monotonously increase or decrease with the increasing of tempering temperature.
\end{abstract}

\section{Introduction}

Hight strength low carbon bainite steel is a new developed steel, which always shows high strength, high toughness and excellent welding performance, and it has been widely used in the engineering machinery, shipbuilding, oil and gas transmission pipeline, etc. Especialy in engineering machinery area, along with the development trends of large scale and lightweight, request for higher yield strength, impact toughness and welding performance of the structural parts has been put forward. At present, the widely used bainite steel with the yield strength of $460 \mathrm{MPa}$ or $550 \mathrm{MPa}$ is mainly prepared by a low cost process named TMCP[1], for the higher yield strength bainite steel, it is widely manufacturated by tempering after reheating and quenching process[2]. As the cost of tempering after reheating and quenching is high, so using tempering after TMCP process to instead it is of great significance. During this new process, through reasonable design of rolling and cooling, the high density dislocation that formed during the low temperature severe finishing rolling can be reserved, then the nuclear point during the phase deformation will be increased, the microstructures is refined, after tempering, the comprehensive mechanical properties of the steel will be finally improved[3]. In this paper, niobium and titanium microalloying steel was chosen as the study object, by tempering after TMCP process, bainite steel with higher yield strength was finally prepared, the effect of tempering temperature on microstructures and mechanical properties of this steel was investigated.

\section{Experimental methods}

The experiments were performed in echeng iron and steel Co.,Ltd. The raw materials are billets with the section size of $250 \mathrm{~mm} \times 1800 \mathrm{~mm}$, its chemical composition is shown in Table 1. Billets were first heated to $1220^{\circ} \mathrm{C}$ in walking beam reheating furnace, kept the temperature for more than 30 minutes, and then rolled to $25 \mathrm{~mm}$ thick plates on four high rolling. The whole rolling were divided into two stages, austenitic recrystallization zone and no austenitic recrystallization zone. In anstenitic recrystallization zone, large pass reduction ratio was used, the total reduction ratio was $68 \%$. In no austenitic recrystallization zone, the total reduction ratio was $60 \%$, among them, the total reduction ration in the last three pass was more than $35 \%$, and the finishing rolling temperature was controlled 
above $840^{\circ} \mathrm{C}$. After rolling, steel plates were cooled to $300^{\circ} \mathrm{C}$ by accelerated laminar cooling, and the cooling rate was above $20{ }^{\circ} \mathrm{C} / \mathrm{s}$.

Samples with the size of $200 \mathrm{~mm} \times 400 \mathrm{~mm}$ were cut from the finished palates, and then tempered in box-type heat treatment furnace under different conditions. With the same tempering time, which was 50 minutes, the tempering temperatures were set at $400^{\circ} \mathrm{C}, 450^{\circ} \mathrm{C}, 500^{\circ} \mathrm{C}, 550^{\circ} \mathrm{C}, 600^{\circ} \mathrm{C}$ and $650{ }^{\circ} \mathrm{C}$ seperately. After tempered, the microstructures and mechanical properties of each treated sample was tested. In this paper, the tensile test was conducted on Zwick/Roell Z250 hydraulic servo tensile testing equipment, $-20{ }^{\circ} \mathrm{C}$ sharpy impact test was performed on SANS ZBC pendulum impact testing machine, microstructures were detected by AXIO optical microscope, and INCA energy disperse spectroscope was used to analyze the chemical composition of precipitates.

Table1 Chemical composition of the raw material (wt $\%)$

\begin{tabular}{cccccccc}
\hline $\mathrm{C}$ & $\mathrm{Mn}$ & $\mathrm{Si}$ & $\mathrm{P}$ & $\mathrm{S}$ & $\mathrm{Mo} 、 \mathrm{Cr}$ & $\mathrm{Nb}$ & $\mathrm{Ti}$ \\
\hline 0.05 & 1.65 & 0.35 & 0.013 & 0.008 & 0.50 & 0.06 & 0.03 \\
\hline
\end{tabular}

\section{Results and discussion}

Effect of tempering temperature on mechanical properties. The effect of tempering temperature on mechanical properties of the steel plates is shown in Fig 1. As the figure showing, the mechanical properties of untreated plate are: the yield strength (Rp0.2) is $735 \mathrm{MPa}$, tensile strength is $955 \mathrm{MPa}$, elongation is $12.5 \%$ and $-20{ }^{\circ} \mathrm{C}$ sharpy impact energy is $175 \mathrm{~J}$. After tempering, the corresponding properties change, and they are affected by the tempering temperature. Below $500{ }^{\circ} \mathrm{C}$, both the yield and tensile strength of the treated plate increase, then decrease and finally increase with the increasing of tempering temperature. Above $500{ }^{\circ} \mathrm{C}$, they decrease with the increasing of tempering temperature firstly, and then almost maintain steady as the temperature reaches $600-650{ }^{\circ} \mathrm{C}$. At this steady state, the yield and tensile strength decrease to $650 \mathrm{Mpa}$ and $750 \mathrm{Mpa}$ seperately. The changing trends of elongation and sharpy impact energy with the increasing of tempering temperature are generally opposite to that of strength. Below $500{ }^{\circ} \mathrm{C}$, the changing trends of elongation and sharpy impact energy are relatively steady. Above $500{ }^{\circ} \mathrm{C}$, the plasticity and ductility of treated plates are obviously improved. So, considering the comprehensive mechanical properties, the steel plates should best be tempered under $550^{\circ} \mathrm{C}$. And under this tempering temperature, the mechanical properties of treated plate are: the yield strength (Rp0.2) is $740 \mathrm{MPa}$, tensile strength is $790 \mathrm{MPa}$, elongation is $16.5 \%$ and $-20{ }^{\circ} \mathrm{C}$ sharpy impact energy is $250 \mathrm{~J}$. As widely known, the mechanical properties change during tempering is mainly controlled by the structure evolution, such as the recovery of dislocation substructure, desolvation of carbon and precipitation of secondry phase[4]. So, microstructures of treated plates are tested and compared.
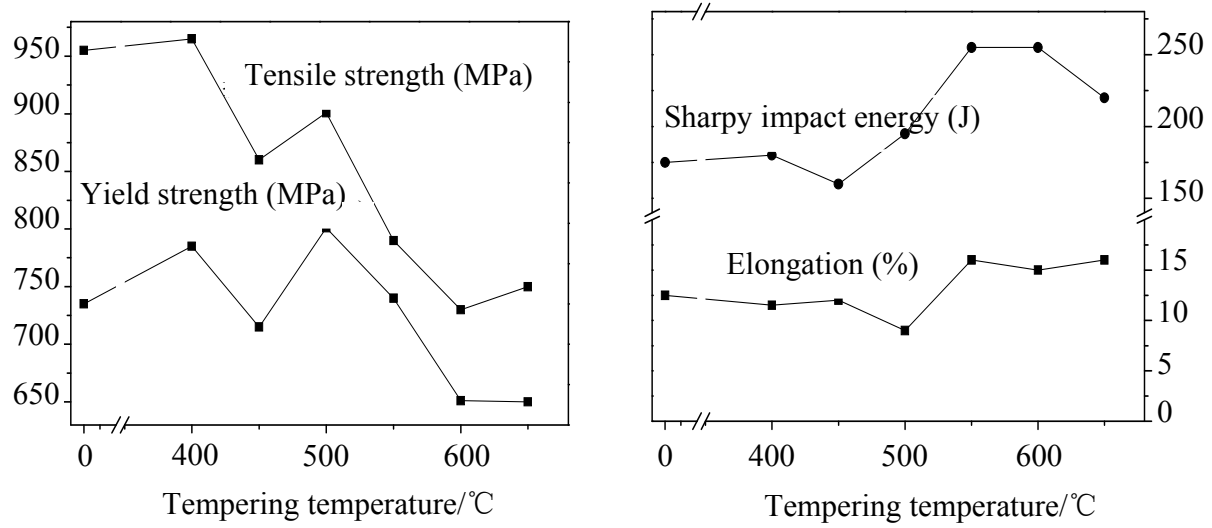

Fig.1 Effect of tempering temperature on mechanical properties of the treated plates 
Microstructure evolution during tempering. The typical microstructures of plates before (TMCP) and after tempering are shown in Fig.2. As shown in Fig.2(a), before tempering, the structure of steel plate is constituted by lath-shaped bainite, austenitc grains' deformation along rolling direction is obviously observed, lots of entangled and lath-shaped bainite distribute among them. Just based on this structure, the stength of the steel is high, but the plasticity and toughness are relatively poor.
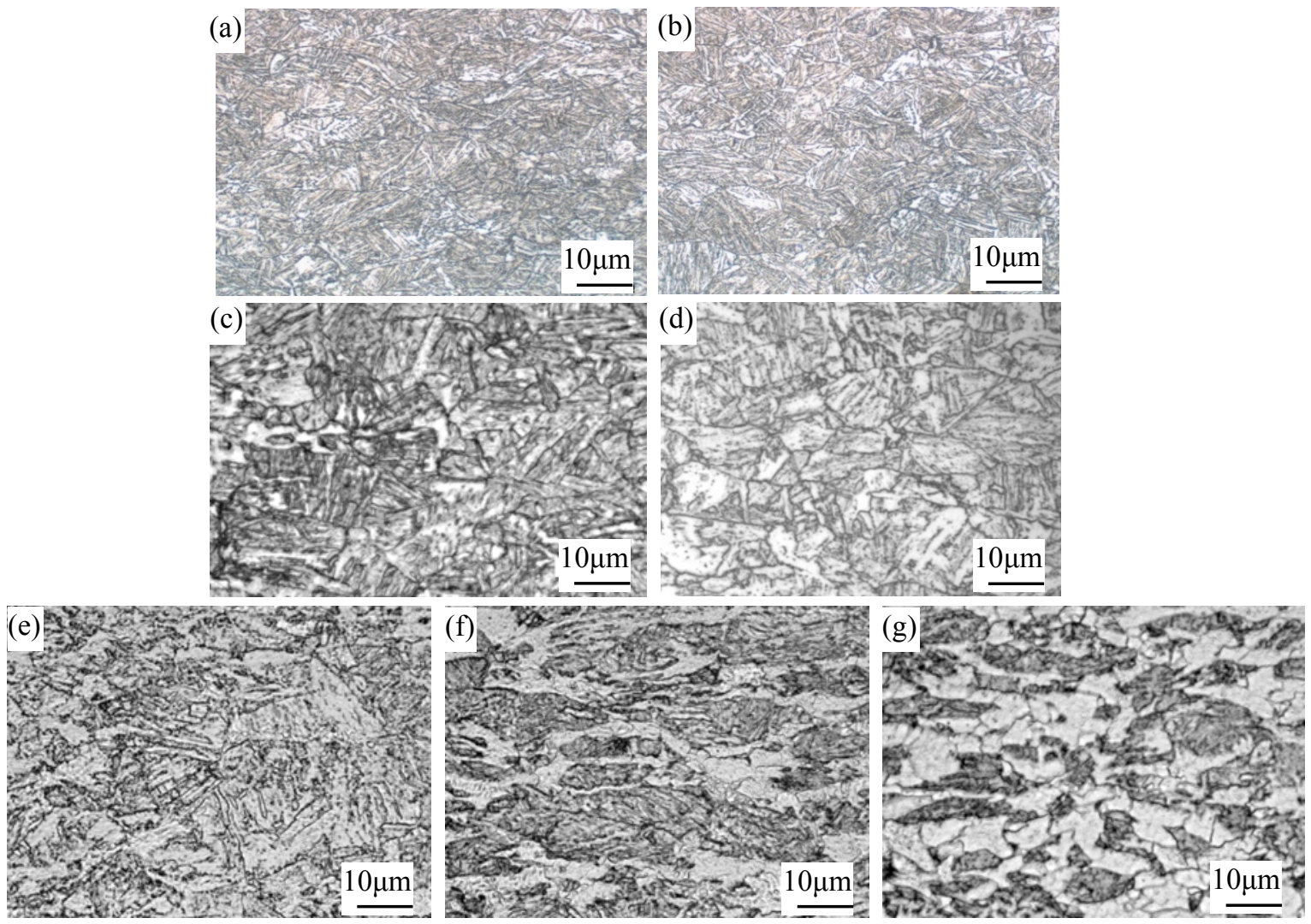

Fig. 2 Microstructures of the plates that tempered under different temperatures
(a) TMCP
(b) $400^{\circ} \mathrm{C}$
(c) $450^{\circ} \mathrm{C}$
(d) $500^{\circ} \mathrm{C}$
(e) $550^{\circ} \mathrm{C}$
(f) $600^{\circ} \mathrm{C}$
(g) $650^{\circ} \mathrm{C}$

When tempered at $400^{\circ} \mathrm{C}$, no obvious change of the structure is observed, as shown in Fig.2(b). However, since a certain amount of niobium and titanium are added into this studied steel, after hot rolling, these alloying elements will supersaturatedly solid solute into the steel. When tempered, precipitates will form. Because of pinning effect to the dislocations from these fine and dispersion distributed precipitates (as shown in Fig.3(a)), the streng of the treated steel is undoubtedly enhanced. However, since the tempering temperature is low, recovery is weak, and the precipitates are harmful to the plasticity of steel, so as compared with untreated plates, the elongation of the steel decreases when tempered at $400^{\circ} \mathrm{C}$.

Increasing the tempering temperature from $400^{\circ} \mathrm{C}$, recovery is enhanced gradually. Due to the movement, merger and restructuring of dislocations, some low angle grain boundaries between lathes disappear, and adjacent lathes merger with each other, then structures are coarsened, as shown in Fig.2(c). Meanwhile, since dislocations density decrease and some substructure are changed during this recovery process, the effect of softening gradually surpass that of precipitation strengthening, then the strength of treated steel decrease. When the temperature reaches $500^{\circ} \mathrm{C}$, precipitates precipitate completely, and their size increase to $30 \mathrm{~nm}$ to $40 \mathrm{~nm}$, as shown in Fig.3(b). Meanwhile, the recovery becomes stable under this tempering temperature. Then at this moment, precipitation strengthening lead the yield and tensile strength increase again and reach their maximum values. Furthermore, due to the precipitation of alloying elements, lattice distortion decreases, and then impact toughness of the treated steel is improved slightly.

With the further increasing of tempering temperature, such as to the range from $500{ }^{\circ} \mathrm{C}$ to $600{ }^{\circ} \mathrm{C}$, due to the growth of precipitates and desolvation of alloying elements, both precipitation 
strengthening and solution strengthening are weakened. Meanwhile, as the tempering temperature is high, recrystallization take place, lath-shaped bainite changes to polygon-shaped ferrite and dislocation defects disappear gradually. Under this condition, softening is undoubtedly enhanced, then the strength of the treated steel decreases sharply[5]. However, because the shape of precipitates change into sphere, lattice distortion decreases and ferrite is formed, the plasticity and toughness of the treated steel plates are improved significantly. When the tempering temperature is above $600{ }^{\circ} \mathrm{C}$, since strengthening and softening achieve balance, so the yield and tensile strength of treated steel almost keep unchanged as the tempering temperature increase continuously. However, as lots of ferrites are formed, the elongation increases slightly, and the structure coarsening lead the impact toughness decreasse slightly. Although the size and shape of precipitates in the steel plates that tempered under different temperatures are different, EDS analysis indicates that the precipitated phase are almost the same, as shown in Fig.3(d), both of them are complex carbonitride containing niobium and titanium.
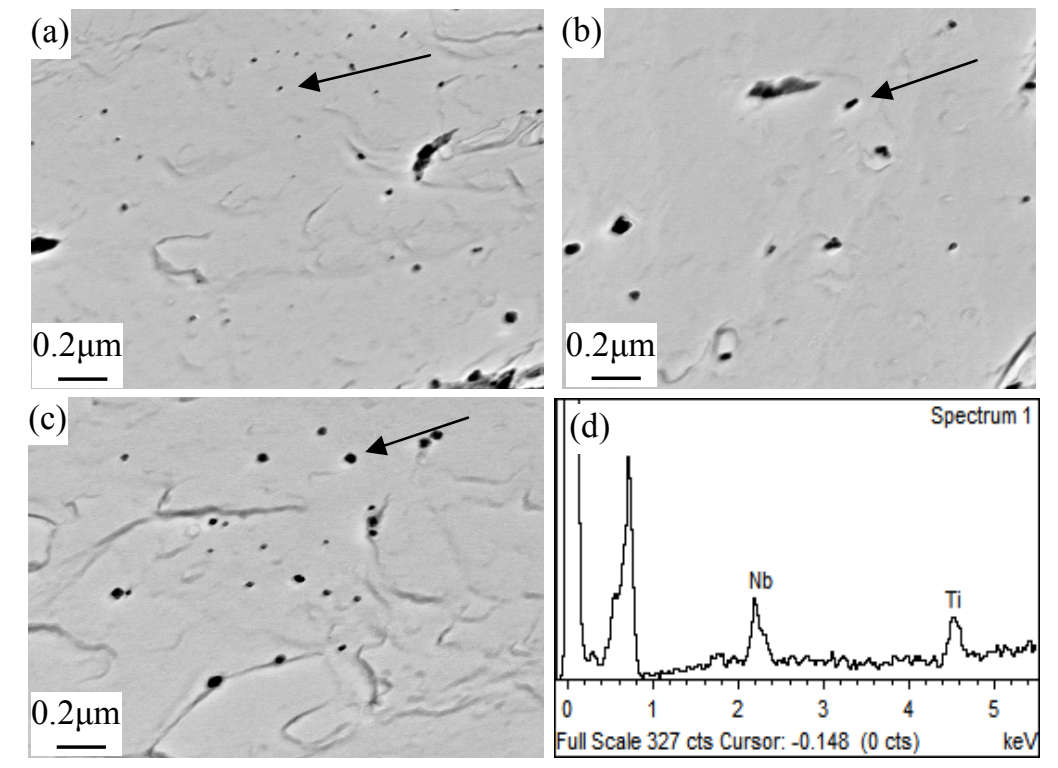

Fig.3 Effect of tempering temperature on precipitates in the treated plates (a) $400^{\circ} \mathrm{C}$ (b) $500^{\circ} \mathrm{C}(6) 600^{\circ} \mathrm{C}$ (d) energy spectrum

\section{Conclusions}

(1) Tempering temperature has an important impact on mechanical properties of treated steel. Considering the comprehensive mechanical properties, the tempering temperature should best be set at $550^{\circ} \mathrm{C}$.

(2) Due to the combined action of precipitation strengthening, recovery softening and alloying elements desolvation, the effect of tempering temperature on mechanical properties of treated steel is complex.

(3) Although the size and shape of precipitates in the steel that tempered under different temperatures are different, the precipitated phase are almost the same.

\section{References}

[1] C.Ouchi: ISIJ Int. Vol. 41(2001): p.542

[2] W.S.Chang: J Mater Sci. Vol. 37(2002): p.1973

[3] K. Shibata, K. Asakura: ISIJ Int. Vol. 35(1995): p.982

[4] D.Y.Huang, I.Froyen: J.Mater.Process.Technol. Vol. 5(2002): p.125

[5] F.C.Gang, M.M.Tu, W.Y.Qing: Mater. Mechanic. Eng. Vol. 30(2006): p.48 